\title{
Incidence and recovery of smell and taste dysfunction in COVID-19 positive patients
}

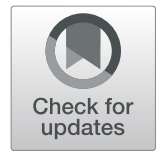

Haider Majid Haider Al-Zaidi ${ }^{1,3^{*}}$ and Hani Musa Badr ${ }^{2}$

\begin{abstract}
Background: This study aims to find the chemosensitive dysfunction incidence in COVID-19-positive patients and its recovery.

We collected the data from sixty-five patients, all COVID-19 positive, quarantined in-hospital between 5 April 2020 and 17 May 2020, by a questionnaire distributed in the quarantine ward.

Results: Smell dysfunction appeared in 89.23\% with or without other symptoms of COVID-19. 39.66\% of them recovered the sense of smell. Taste dysfunction found in 83.08\% patients with other COVID-19 symptoms. Only $29.63 \%$ of them recovered. The recovery took 1-3 weeks, and most cases recovered within 1 week or less. 18.46\% and $15.38 \%$ had smell and taste dysfunction, respectively, as the only symptom before COVID-19 confirmation. Most of the chemosensitive dysfunction affected the 4 th decade of age in this study.

Conclusion: Chemosensitive dysfunction is associated with coronavirus disease and may be the only symptom that presents the disease. This makes the ENT doctors the first line of contact with the coronavirus. Further objective studies are required to cover chemosensitive dysfunctions, as the recognition of this dysfunction may help the diagnosis of COVID-19, and prevent the spread of this disease.
\end{abstract}

Keywords: Chemosensitive dysfunctions, Anosmia, Taste loss, COVID-19

\section{Background}

There are three types of presentations in COVID-19: asymptomatic, mild upper respiratory tract infection (URTI), and severe systemic disease such as bilateral interstitial pneumonia [1].

Olfactory dysfunction (OD) is already recognized in ENT practice after many viral infections, which can cause OD by inflammation in the sinonasal mucosa and runny nose, with rhinovirus, parainfluenza Epstein-Barr virus, and some coronavirus being the most common viruses [2].

In 2018, Dubé et al. found that the previous form of human coronavirus ( $\mathrm{HCoV})$ OC43 reaches the

\footnotetext{
* Correspondence: hmh7895@gmail.com

'College of Medicine, Ibn Sina University of Medical and Pharmaceutical Sciences, Baghdad, Iraq

${ }^{3}$ Baghdad, Iraq

Full list of author information is available at the end of the article
}

central nervous system through the olfactory epithelium and starts neuropropagation at the olfactory bulbs [3]. Many other recent studies found that smell and taste dysfunctions are seen frequently in COVID19 patients [4]. Therefore, it is logical to consider the relationship between OD and the new coronavirus disease 2019.

In Iraq, the COVID-19 affected the public life, as in all other affected countries, and since the pandemic, there was an increase in the reported cases of OD and taste loss in hospitals and private clinics.

Thus, we are investigating the incidence in OD and taste disorders as an isolated symptom of coronavirus disease in Iraqi patients.

\section{Methods}

We collected the data from sixty-five patients, all COVID-19 positive, quarantined in quarantine hospital 


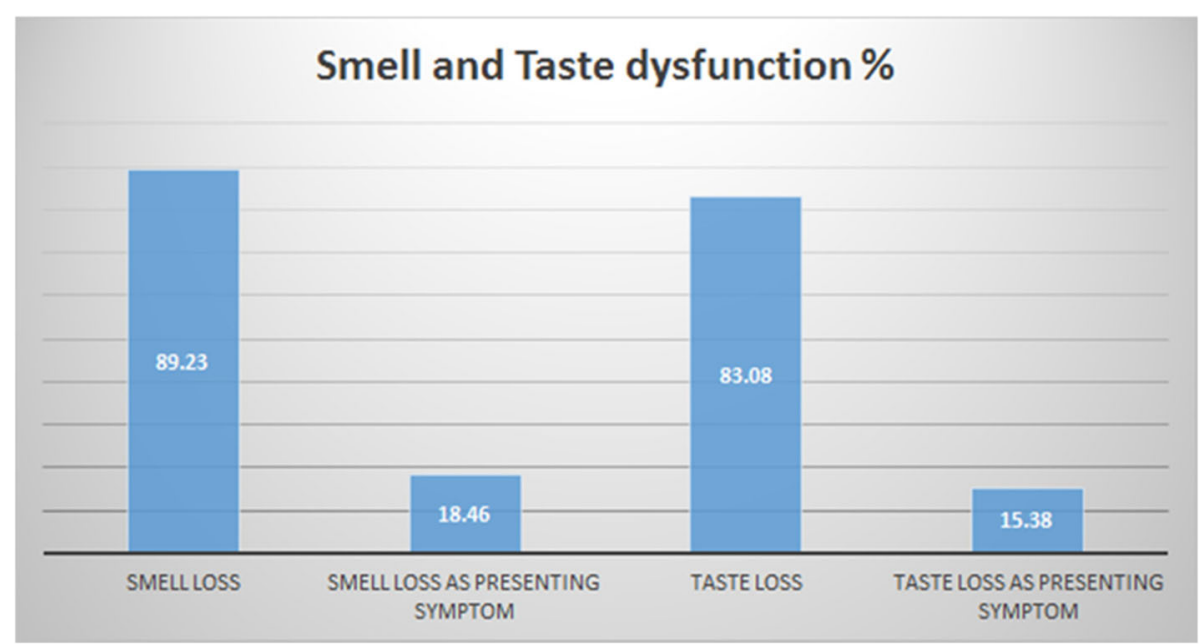

Fig. 1 The percentage of smell and taste loss in general and as the only presenting symptom of COVID-19

between 5 April 2020 and 17 May 2020, by a questionnaire distributed the quarantine ward.

The patients were included if they were proved to be positive for COVID-19, and they are fully conscious and had willingly given the formal consent of being enrolled in the research.

We excluded patients who had olfactory problems before January 2020.

\section{Results}

Sixty-five COVID-19-positive patients, 27 males (41.54 $\%)$ and 38 females (58.46\%), average age 41.2 years

Smell dysfunction appeared in 58/65 (89.23\%) patients with or without other symptoms of COVID-19; twelve of them had been tested for COVID-19 because they were in contact with other positive symptomatic patients. All these 12/65 (18.46\%) patients confirmed that they had no symptoms other than loss of sense of smell before they were tested for COVID-19, and 10/65 (15.38\%) patients had taste loss in addition (Fig. 1).

Taste dysfunction was found in 54/65 (83.08\%) patients with other COVID-19 symptoms. Only 16/54 (29.63\%) of them recovered.

Anosmia was mild in 39/58 (67.24\%) patients; of them, $16 / 39$ (41.03\%) were male, and 23/39 (58.97\%) were

Table 1 Anosmia severity gender distribution

\begin{tabular}{llllllll}
\hline $\begin{array}{l}\text { Anosmia } \\
\text { severity }\end{array}$ & Number & Number \% & Male & Male $\%$ & Female & Female \% \\
\hline Mild & 39 & 67.24 & 16 & 41.03 & 23 & 58.97 \\
moderate & 11 & 18.97 & 5 & 45.45 & 6 & 54.55 \\
$\begin{array}{l}\text { Complete } \\
\text { anosmia }\end{array}$ & 13.79 & 3 & 37.5 & 5 & 62.5 \\
Total no. & 58 & 100 & & & & \\
\hline
\end{tabular}

female. Eleven of 58 (18.97\%) had moderate anosmia; of them, 5/11 (45.45\%) were male, and 6/11 (54.55\%) were female. Eight of 39 (20.51\%) had complete anosmia, 3/8 (37.5\%) were males and 5/8 (62.5\%) females (Tables 1 and 2; Figs. 2 and 3).

The timing of smell loss appearance in relation to the COVID-19 confirmation by PCR \pm CT scan was only 1 / $58(1.72 \%)$ after the confirmation. However, appearance before confirmation had variable timing. Twelve of 58 (20.68\%) appeared within less than a week before confirmation, while 18/58 (31.03\%) appeared before 1 week. In addition, some patients took a longer time between smell loss and confirmation; 19/58 (32.76\%) of them took 2 weeks, $6 / 58$ (10.34\%) took 3 weeks, and $2 / 58$ (3.45\%) 1 month or more.

Twenty-three of 58 (39.66\%) patients had the sense of smell recovered. The recovery took $1-3$ weeks to occur. The time taken to recover the smell distributed as $21.74 \%$ recovered within less than a week, $52.17 \% 1$ week, $21.74 \%$ within 2 weeks, and $4.35 \% 3$ weeks.

The timing of taste loss appearance in relation to the COVID-19 confirmation was only 4/54 (7.41\%) after the confirmation. Appearance before confirmation had variable timing also as in smell. Where 4/54 (7.41\%) had taste loss within less than a week before confirmation,

Table 2 Taste loss severity gender distribution

\begin{tabular}{lllllll}
\hline $\begin{array}{l}\text { Taste loss } \\
\text { severity }\end{array}$ & number & $\boldsymbol{n} \%$ & Male & Male \% & Female & Female \% \\
\hline Mild & 37 & 68.52 & 15 & 40.54 & 22 & 59.46 \\
Moderate & 12 & 22.22 & 7 & 58.33 & 5 & 41.67 \\
$\begin{array}{l}\text { Complete } \\
\text { taste loss }\end{array}$ & & 9.26 & 2 & 40.00 & 3 & 60.00 \\
Total no. & 54 & 100.00 & & & & \\
\hline
\end{tabular}



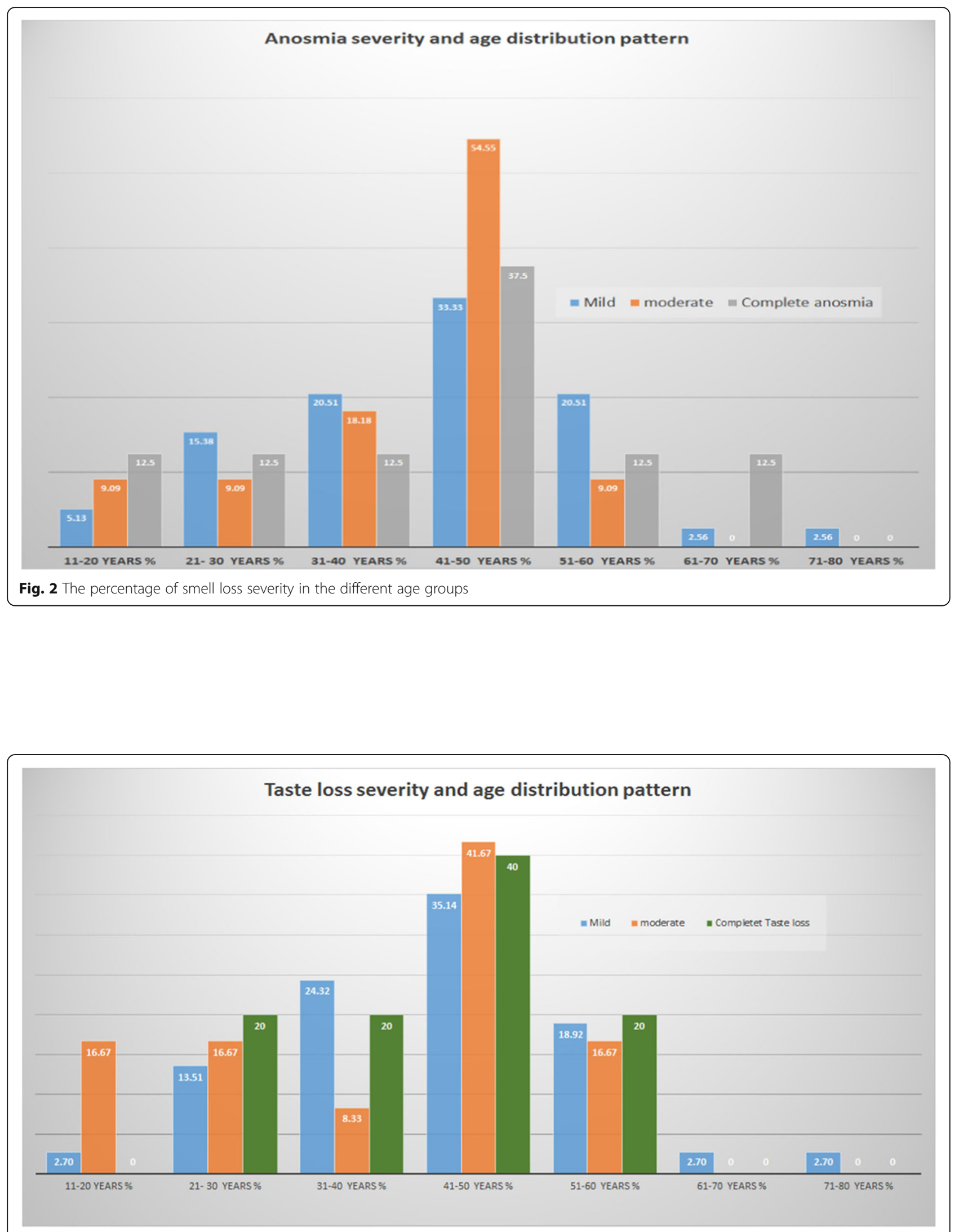

Fig. 3 The percentage of taste loss severity in the different age groups 
18/54 (33.33\%) before 1 week, 15/54 (27.78\%) before 2 weeks, 10/54 (18.52\%) before 3 weeks, and 3/54 (5.56\%) 1 month or more before confirmation (Fig. 4).

The time for taste recovery distributed as $25 \%$ recovered within less than a week, $50 \%$ in a week, $18.75 \%$ within 2 weeks, and $6.25 \%$ in 3 weeks (Fig. 5).

The most common complaints were high temperature $(63.08 \%)$, cough $(60.00 \%)$, headache $(52.31 \%)$, dyspnea $(47.69 \%)$, both sore throat and diarrhea $(32.31 \%)$, and chest pain or tightness (30.77\%). Figure 6 show the percentage of different patients' complaints.

Fifty-seven patients $(87.69 \%)$ were non-smokers, while only eight (12.31\%) patients were smokers.

\section{Discussion}

Viral infections are common causes of loss of smell, and many cases of transient loss may be missed [5]. Over the last 2 months, an increase of sudden isolated anosmia incidence, with or without taste loss, was reported. In this study, chemosensitive dysfunction appeared in high percentage of the COVID-19 patients, $89.23 \%$ of patients had smell dysfunction and $83.08 \%$ had taste dysfunction $[2,6]$.

Sudden isolated chemosensitive dysfunction appeared in $18.46 \%$ and $15.38 \%$ for anosmia and taste loss, respectively. Interestingly, these percentages were reported in patients who were tested because of only contact with COVID-19 relative; two of them reported the loss of smell as the first symptom, while other 10 patients reported no first complaint except contact with COVID -19 patient, and when it comes for the symptoms questionnaire, they had reported only chemosensitive dysfunction.

Females gender was more affected in this study, although with little difference. This may be because many male patients refused giving consent to participate. However, other studies reported this gender percentage [5-8].

Most cases were mild, followed by moderate, then total anosmia and or taste loss. There must be recognition of the patient feeling to have chemosensitive disorders and the real presence of such dysfunction, i.e. the subjective and objective chemosensitive dysfunction. More subjective studies that investigate the taste and smell dysfunction are needed, although it is difficult to conduct such study because the risk of spread of infection.

The age group distribution shows most chemosensitive dysfunctions were in the fourth decade and around it [9].

Regarding timing of chemosensitive dysfunctions in relation to the confirmation of COVID-19, more than half of patients with dysfunction appeared 1 week or less before confirmation, which may give a clue to the cause of this dysfunction.

Recovery of chemosensitive dysfunction occurred within 1-3 weeks; most of them recovered within the first week [2]. This means the dysfunction is transient in most of the cases and reversible. Most of them did not take specific treatment for the chemosensitive dysfunction.

Majority of patients were non-smokers as shown by other studies [2, 10]. The relation of smoking to

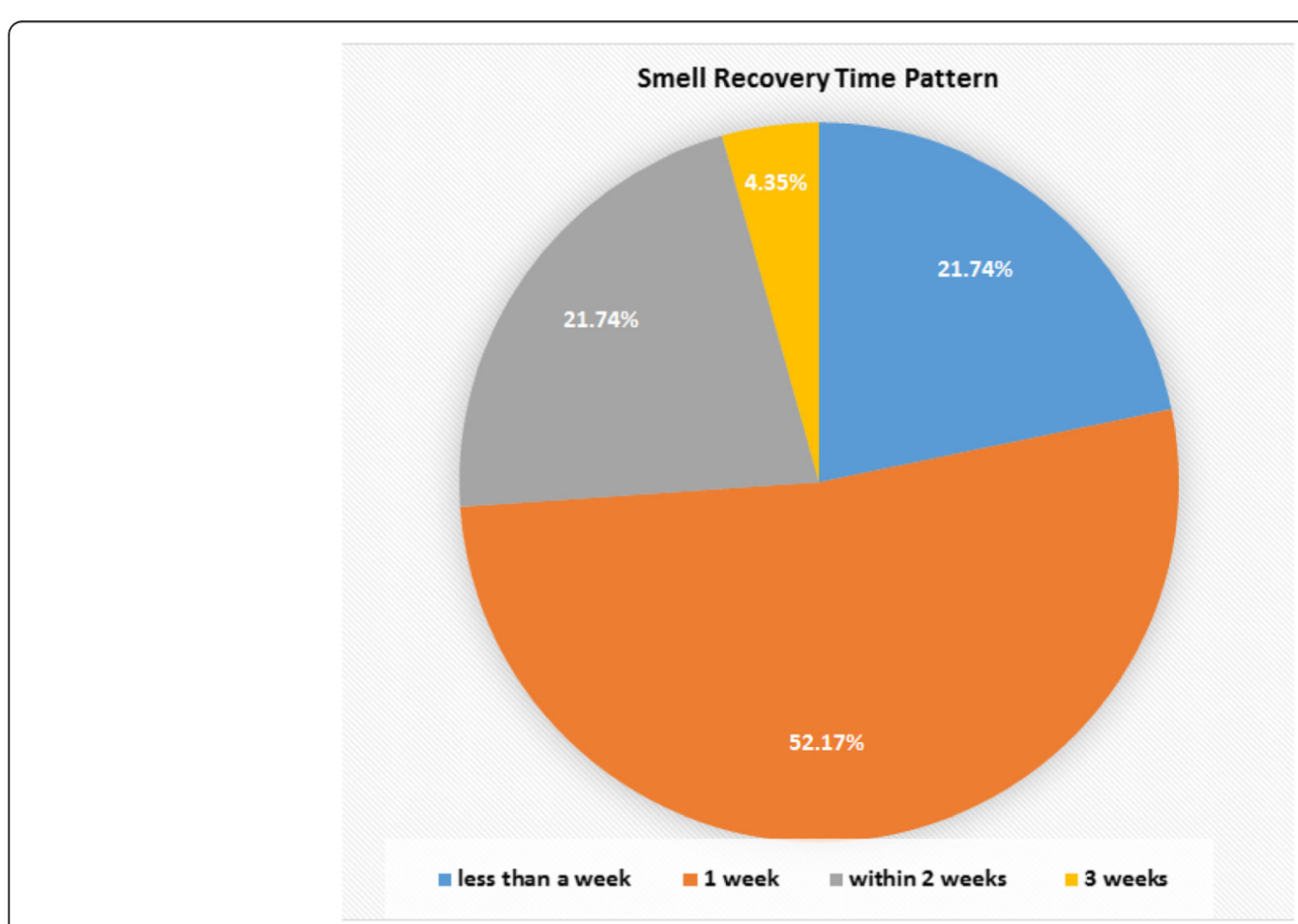

Fig. 4 The percentage of smell recovery in the corresponding periods 


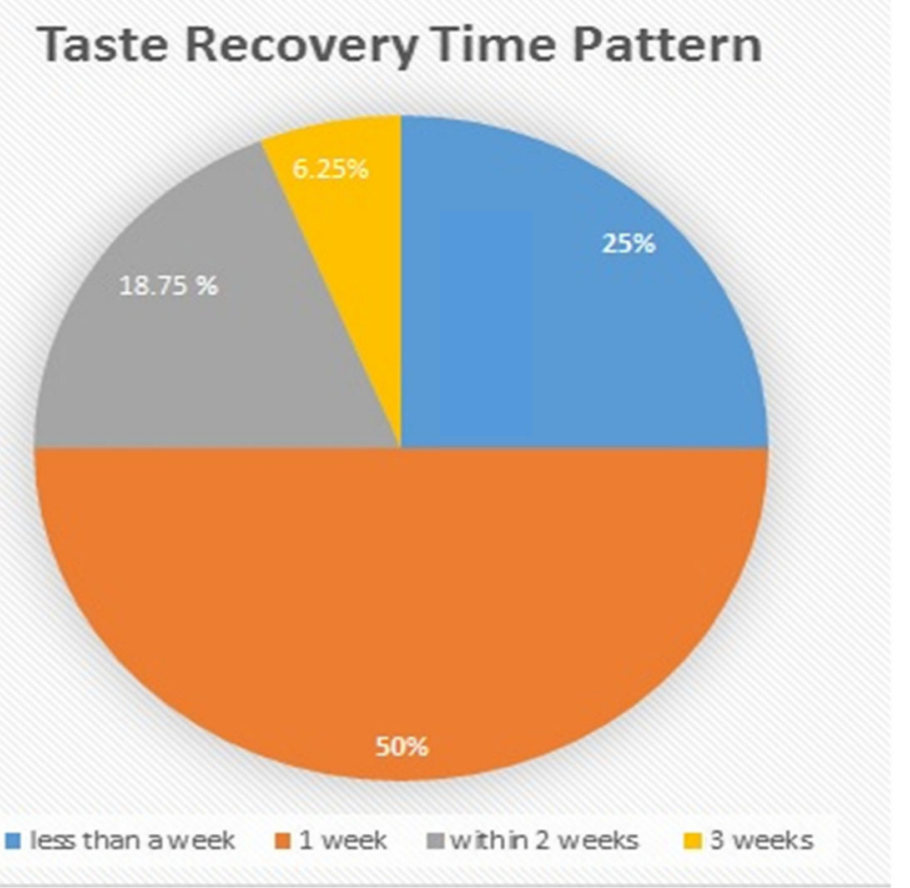

Fig. 5 The percentage of taste recovery in the corresponding periods

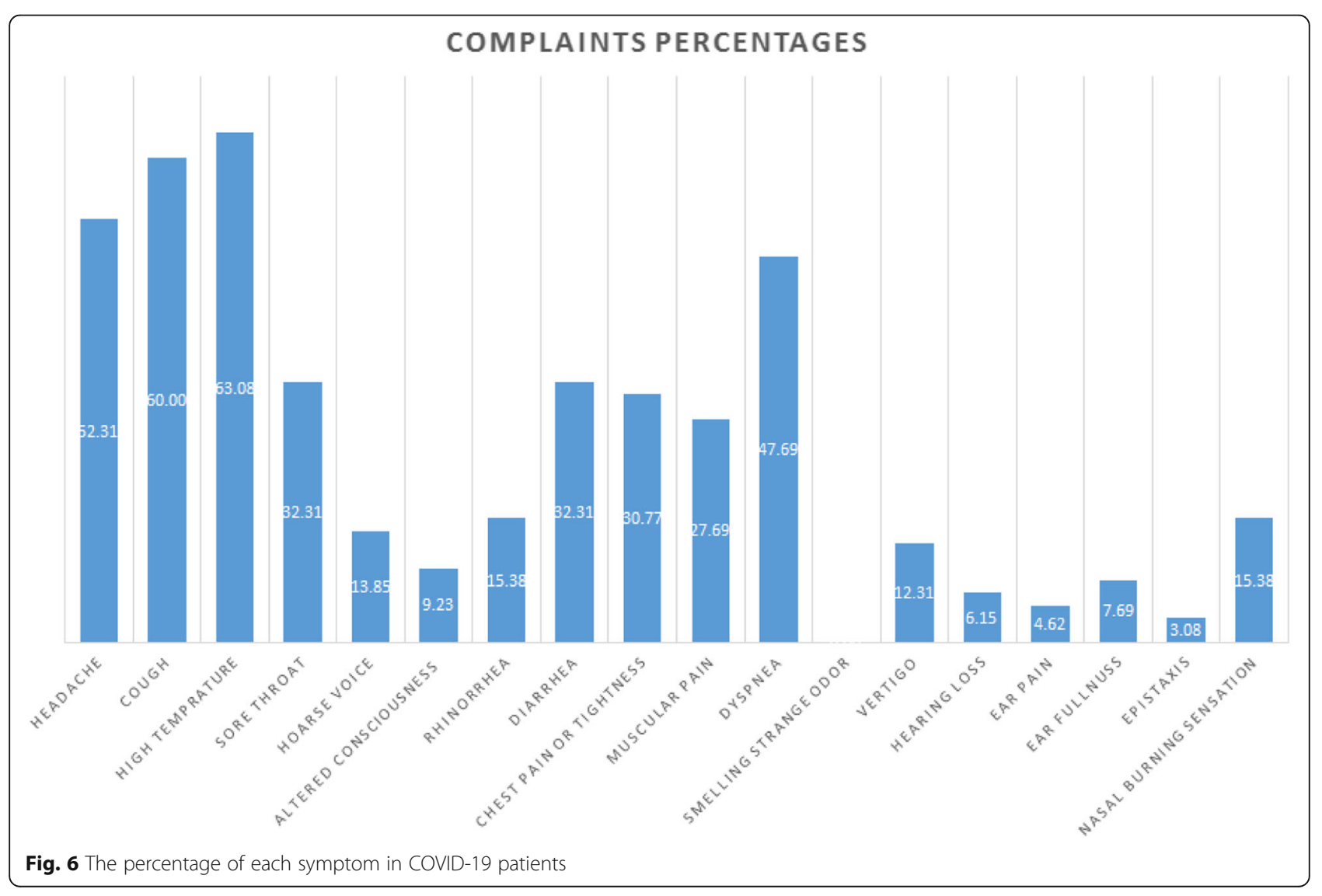


COVID-19 is interesting and needs to be investigated in further studies.

\section{Conclusion}

Chemosensitive dysfunction is associated with coronavirus disease and may be the only symptom that presents the disease. This makes the ENT doctors in the first line of contact with coronavirus. Further objective studies with larger sample are required to cover chemosensitive dysfunctions, as the recognition of this dysfunction may help the COVID-19 diagnosis, and prevent the spread of this disease.

\section{Abbreviations}

COVID-19: Coronavirus disease 2019; HCoV OC43: Human coronavirus (strain OC43); OD: Olfactory dysfunction; URTI: Upper respiratory tract infection

\section{Acknowledgements}

We are grateful to the help of Dr. Abdul Kareem Sadiq Kareem, vice director of Al-Shifaa hospital in Baghdad, who facilitated data collection. We would like also to express our extreme gratitude to Dr. Nadia Noori Hasan, member of Iraqi Translators Association and lecturer doctor at Ibn Sina university of medical and pharmaceutical sciences, for linguistic review of the manuscript.

\section{Authors' contributions}

$\mathrm{HMH}$ and $\mathrm{HMB}$ contributed to the concept, design of the study, data collection, data analysis, and revised the manuscript for important intellectual content and approved the final version. $\mathrm{HMH}$ made the drafting of the manuscript. The author(s) read and approved the final manuscript.

\section{Funding}

No funding was provided for this research of any kind.

\section{Availability of data and materials}

The authors confirm that data and materials are available.

\section{Ethics approval and consent to participate}

This study was approved by the institutional review board (IRB) - ethical committee at Ibn Sina University of medical and pharmaceutical sciences on the 2 nd of April 2020. Participants given the formal consent of being enrolled in the research.

\section{Consent for publication}

Written informed consent for the publication was obtained from the participants. As a consent to publish the anonymous data was written in the end of questionnaire provided.

\section{Competing interests}

The authors declare that they have no competing interests.

\section{Author details}

${ }^{1}$ College of Medicine, Ibn Sina University of Medical and Pharmaceutical

Sciences, Baghdad, Iraq. ${ }^{2}$ Gazi Alhariri Hospital, Baghdad, Iraq. ${ }^{3}$ Baghdad, Iraq.

Received: 23 June 2020 Accepted: 5 October 2020

Published online: 31 October 2020

\section{References}

1. Gane SB, Kelly C, Hopkins C (2020) Isolated sudden onset anosmia in COVID-19 infection. A novel syndrome? [published online ahead of print, 2020 Apr 2]. Rhinology. https://doi.org/10.4193/Rhin20.114

2. Lechien JR, Chiesa-Estomba CM, De Siati DR et al (2020) Olfactory and gustatory dysfunctions as a clinical presentation of mild-to-moderate forms of the coronavirus disease (COVID-19): a multicenter European study [published online ahead of print, 2020 Apr 6]. Eur Arch Otorhinolaryngol.:111. https://doi.org/10.1007/s00405-020-05965-1

3. Dubé M, Le Coupanec A, Wong AHM, Rini JM, Desforges M, Talbot PJ (2018) Axonal transport enables neuron-to-neuron propagation of human coronavirus OC43. J Virol 92(17):e00404-e00418 Published 2018 Aug 16. doi: 10.1128/JVI.00404-18

4. Vaira LA, Deiana G, Fois AG et al (2020) Objective evaluation of anosmia and ageusia in COVID-19 patients: single-center experience on 72 cases. Head Neck:1-7. https://doi.org/10.1002/hed.26204

5. Hopkins C, Sruda P, Kumar N (2020) Presentation of new onset anosmia during the COVID-19 pandemic. Rhinol. https://doi.org/10.4193/Rhin20.116

6. Angelo Vaira L, Hopkins C, Salzano G et al (2020) Olfactory and gustatory function impairment in COVID-19 patients: Italian objective multicenterstudy. Head Neck.:1-10. https://doi.org/10.1002/hed.26269

7. Mao L, Wang M, Chen S et al (2020) Neurological manifestations of hospitalized patients with COVID-19 in Wuhan, China: a retrospective case series study. MedRXiv. https://doi.org/10.1101/2020.02.22.20026500

8. Giacomelli A, Pezzati L, Conti F, Bernacchia D, Siano M, Oreni L, Rusconi S, Gervasoni C, Ridolfo AL, Rizzardini G, Antinori S, Galli M. Self-reported Olfactory and Taste Disorders in Patients With Severe Acute Respiratory Coronavirus 2 Infection: A Cross-sectional Study. Clin Infect Dis. 2020;71(15): 889-90. https://doi.org/10.1093/cid/ciaa330.

9. Hopkins C, Surda P, Whitehead E et al (2020) Early recovery following new onset anosmia during the COVID-19 pandemic - an observational cohort study. J Otolaryngol Head Neck Surg 49:26. https://doi.org/10.1186/s40463020-00423-8

10. Bagheri SH, Asghari A, Farhadi M, et al. Coincidence of COVID-19 epidemic and olfactory dysfunction outbreak in Iran. Med J Islam Repub Iran. 2020;34: 62. https://doi.org/10.34171/mjiri.34.62.

\section{Publisher's Note}

Springer Nature remains neutral with regard to jurisdictional claims in published maps and institutional affiliations.

\section{Submit your manuscript to a SpringerOpen ${ }^{\circ}$ journal and benefit from:}

- Convenient online submission

- Rigorous peer review

- Open access: articles freely available online

High visibility within the field

- Retaining the copyright to your article

Submit your next manuscript at $\boldsymbol{\nabla}$ springeropen.com 